\title{
Mental Health Workers Play Different Roles in the District Mental Health Service
}

\author{
Torill M. Sæterstrand, Solrun G. Holm \\ University of Nordland, Bodø, Norway
}

\begin{abstract}
Introduction: Mental health workers play different roles in the District Mental Health Service. They differs in professional education skills. Taking care of psychotic patients also include to administrate and observation the medication in practice. There are different experiences in this area. Objectives: To gain knowledge about the practice in the District Mental Health Service according to medication trends. Aims: To gain knowledge and information about the daily practice. Methods: This pilot study was done in 2011. Focus-group interviews were made with leaders and professional health workers in two groups, from two different municipalities in Northern Norway. Literature reviews were also done. Findings: The results show that the District Mental Health Service practice differed in organization of the service. The one who has responsibility of medicine given to the patients on a daily basis also varied. The most educated personnel the psychiatric health team in the municipalities took care of treatment only in communication with the psychiatric patients, while the lowest educated personnel in the home care service administrated the patients' medicine. Some of the workers in the home care settings had only a 10 hours medical course. They were afraid of the patients who could be aggressive and denied to take medication. Conclusion: The organization of the medication responsibility needs to be more focused on because of the need of good observation on how the medicine affects the patients.
\end{abstract}

Keywords: medication, mental health service, observation, organization

\section{Introduction}

Mental health workers play different roles in the District Mental Health Service, and they have different amounts of professional education. Taking care of psychiatric patients includes administration and observation of how the medication is given, but there are different experiences in this area. We wanted to gain knowledge about the practice in the District Mental Health Service according to medication trends, and gain information about the daily practice. Literature reviews show that there are few studies on this topic.

\section{Theoretical Frameworks}

Poole and Grimes' (1998) study in England, show that patients wanted to get their depot injections at home. The focus on user involvement was the reason for implementing this study into practice, and they also found that having the possibility for observing the patient's surroundings at home were better than if the

Torill M. Sæterstrand, Cand.san, RN, MH, Ph.D. Candidate, associate professor, Faculty of Professional Studies, University of Nordland.

Solrun G. Holm, Cand. san, RN, IN, Ph.D. Candidate, associate professor, Faculty of Professional Studies, University of Nordland. 
patients only got six minutes of observation at the doctor's office when given their injections. Cocoman and Murray's (2008) study in Ireland shows that depot injections given by nurses, both historically and today, is injected in the dorsoglutear site. Wynaden et al.'s (2006) did an Australian study on the best practice for depot injections. They did a review of 300 abstracts, 150 articles, interviewed 93 nurses and studied the practice of intramuscular injections on 96 patients. They found that $71.9 \%$ of the patients got their injections in the dorsoglutear site and $28.1 \%$ were given it into other recognized injection sites as ventrogluteal, vastus lateralis, and deltoid. They concluded that there was a need for further education for the nurses. Rock's (2000) study on the administration of intramuscular injections found that there was no lesser pain for the patient by using two needles, but argued for more research into the topic. Gray, Smedley, and Thomas (1997) did a survey in Canada among 100 patients and found out that $88 \%$ of the patients got depot injections, and that patients over 50 years old were more common to get depot injections. Besenius, Clark-Carter, and Nolan (2010) studied the health professionals' attitudes for depot injections. They did a review and found six papers out of 131 that described this problem. Mental health professionals have different beliefs about depot injections, like these: "they are old fashioned", "stigmatizing", "not acceptable to patients", "have severe side effects", "high costs", and "are only needed when they think the patients are not adhering to oral medication". Muir-Cochrane's (1998) ethnographic study in Australia on nurses experiences with neuroleptical depot injections, show that the nurse is not only a "needle-nurse", but something more. The nurse's ability to make an atmosphere of distress and calm situations for the patients made the injection situation for the patients much better. Phillips and Mccann (2007) interviewed 10 persons in England - suffering from schizophrenia - about their opinion of the nurse's therapeutic treatment with neuroleptic injections. They used a semi structured interview scheme which included 20 questions. The researchers found that the relationship between patient and nurse, as this study reveals, was that the situation not only was therapeutic, but also provided a forum where psychosocial and clinical issues could be discussed and explored. The users of the service felt they had a role and an influence in the giving of their care. The different studies show that this area is in need of more research. This field is also changing according to new reforms and the role of the health personnel and of the patient needs to be focused on. This paper explores how, within the process of taking care of the patients and the administration of the medication, health workers are able to take care of their patients' needs in different ways. The statement of the problem was: "What are the different experiences and thoughts on the medication practice in the District Mental Health Service?"

\section{Design and Methods}

It has been chosen a descriptive design where the method is qualitative research. Literature reviews were also made, but there were few studies made on this topic. This pilot study was done in 2011 where data was collected by doing two focus-group interviews. The interview-guide was semi-structured with questions with themes as: organizing, roles, medication practice, observation, caring, competence, and cooperation.

\section{Sample}

The selection consisted of eight employees with further education within psychiatric health work. The informants were leaders and professional health workers in two different municipalities in Northern Norway. The inclusion-criteria for the health workers and the leaders were a minimum of a three year experience in the District Mental Health Service, and some of the informants also had over 15 years of experience from 
Psychiatric Institutions. The leaders and the health workers were interviewed in two different focus groups, one group in each municipality.

\section{Reliability and Validity Issues}

The leader at the District Mental Health Service in the municipalities recruited the persons who gave their consent to be interviewed.

The informants were given information about the project, including a permission scheme, and the interviews were based on voluntary participation. The validation of the study depends on finding meaning in the phenomena studied, and the way the questions were asked during the interviews. The validation was taken care of throughout the collection of data and during the data analysis. The reliability was taken care of in the process of data collection, in the structure and in the analyzing of the data. The interviews were transcribed word by word.

The validation in this study depends on creating meaning out of the phenomena that is studied, and the way the questions were asked dialogically during the interviews, for example, "Did I understand you correct when you said...". The study only includes eight informants, but the data gave a rich and nuanced overview of the informants' experiences after all. The comparing with other similar studies strengthens the study's validity. Validity and reliability were taken care of throughout the whole study. The informants showed a great deal of openness during the interviews and the data is therefore considered as trustworthy and relevant. The responsibility of the analysis is taken care of by two experienced researchers and interview sentences are taken care of, and some of them are shown in the results.

\section{Datacollection}

The collection of data is done by following Kvale's (1997) description of qualitative research interviews. A qualitative interview is defined by Kvale (1997) as an interview which goal is to obtain description of the person interviewed lifeworld, with a view to interpretation of the described phenomena. The aim of this method is to obtain knowledge on the health personnel's own experiences. It is desirable to get an insight on how the interviewed look upon their situations, and that there is prepared an interview-guide with open questions. The interviews were carried out on the basis of a semi-structured interview-guide, but the questions also followed up what the informants talked about. It was adapted for the most possible open conversation to bring out the informants' experiences.

Since we were two researchers, it was possible to both observe the conversation and to give questions. According to Krueger (1994), the aim of focus-group interviews is to get a precise discussion with the aim of getting more knowledge on a well-focused question in a safe and non-threatening environment. Focus-groups have as a knowing that they consist of people with the same interests and background. The data was directly transcribed. All interviews were read several times. After the first read-through, the themes that came to light in the interviews were brought out.

\section{Data Analysis}

The analysis is inspired by Kvale's (1997) content analysis. The analysis was done by following Kvale's three phases in the analysis of the material (content analysis): self-understanding, critical understanding based on common sense, and theoretical understanding. The first phase of self-understanding is the informants' sentences. The next phase is to critically understand the researcher's commitment to the informants' sentences. The analysis has here a broader frame of understanding than the informants own. The theoretical understanding 
is the third phase, where the theoretical framework and results from other studies are brought into the discussion to fill out the perspective. The first reading of the text resulted in themes which also had their roots in the interview guide and in the aim of the study. Then the whole manuscript was read over to systemize the text and to find main- and sub-categories. The next step was doing a theoretical analysis by bringing the categories together into meaningful units. The written material was further interpreted in the light of the following perspectives (Kvale, 1997):

(1) Self-understanding — as it was put forward by the employees during the interviews;

(2) Critical understanding — based on the qualitative analysis done by the researchers;

(3) Theoretic understanding - where theoretic framework helped to shed light on the findings that occurred.

The recordings were first listened through in order to get a general impression of the contents. Afterwards, the interviews were directly transcribed. The interview material was then structured, and in the following work the interview's meaning was developed and interpreted, and systemized in categories and subcategories that in this article appears in following categories in the result chapter. To ensure trustworthiness, a concentration of the findings was discussed with two of the informants, both managers, and the meant the findings gave a correct picture of the situation in practice.

\section{Ethical Considerations}

The research project was given supervision from the Regional Committee of Ethics (Northern Norway) in 2011 and the study was done by following the Helsinki Declarations ethical guidelines. The registration number in REK is 2011/2457-6 (Document-id is nr. 181546). Since the data material is indirectly person-identifiable, it is anonymised. A notification of the project was sent to the NSD (Norwegian Social Science Data Services) and the study was advised in 2011 with the nr. 28643. Verbal information and written approvals were given as described in the Helsinki-Declaration. The participants were given information about the study and were informed that their participation would not affect the help they received and they got both oral and written information about the possibility to withdraw themselves from the study if they wanted. The participants were informed that the data from the interviews could be published in international articles as well as at conferences.

\section{Findings}

The findings show that the District Mental Health Service practice varied in organization of the service in the two municipalities. The one who has the responsibility of medication for the patients in daily settings differed. The most educated persons in the District Mental Health Care team treated the patients in therapy session, while the lowest educated personnel in the Home Care service administrated the patients' medicine. Some of the workers in the home care service had only a 10 hours medical course. They were afraid of the patients who could be aggressive and denied to take medication.

\section{Findings}

The findings are as follows:

(1) Differences in the organizational structure;

(2) Performance of the service;

(3) Medication practice;

(4) Different communication skills; 
(5) Observation of patients;

(6) Home visitors role;

(7) Caring in practice.

\section{Differences in the Organizational Structure}

In these two municipalities, the organization of the District Mental Health Service was different, but not in the organization of administration of medication, which were the same in both municipalities. The administration of medication was the Home Care service's responsibility.

One informant says,

The Home Care service is not willing to give the psychiatric patients their medicine because they sometimes act threatening and are scaring us, and refuses to take their medicine. We feel that the Psychiatric Health Service, who are more educated in this area than we are, should administrate the medicine because they know better how to communicate and act together with psychiatric patients.

The staff at the District Mental Health Service consisted of a few educated nurses, child welfare social worker, and social workers with specialist education in mental health. In one municipality, the staff was 15 persons, in the other there were 12, but the inhabitants in both municipalities are 10,000. In one municipality, the District Mental Health Service has four different units with one leader administrating each field: the psychiatric activity center, the milieu-therapy, the communication therapists, and a shielded shared house where patients with mental health diagnosis lived. The communication therapists had special education in psychotherapeutic communication and held the therapy sessions at their office organized at the District Mental Health Service. Once a week they had meetings where the different fields cooperated and the leaders of the different units made their decisions on how new patients should get help and treatment, and others could be evaluated. The other municipality had two different units; a shielded shared house and communication therapists.

\section{Performance of the Service}

The performance of the service given in the District Mental Health Service was to take care of the patients in different ways: communication-therapy and daily activities with focus on user participation and empowerment. They had several meetings during the week and did not work in the afternoon, weekends or nights, like in the Home Care service.

The responsibility of the patients was in a way divided, and there were boundaries between the staff in the District Mental Health Service and the Home Care service. The shielded flat had its own personnel who worked in the evenings. At day time, the personnel were both visiting the patients in their flat in the shielded shared house, and patients who lived in their own homes. The patients who lived in the shielded shared house were younger patients in one municipality, but in the other municipality the patients in the shielded shared house were middle-aged. The young patients from 18-30 were priority number one in both municipalities, and they pointed out that communication-therapy was in focus in both places, and that was what they were educated in and wanted to work with in their daily practice. One informant in the District Mental Health Service says,

When I first started working here, the ages were mainly above 60 years old. I think that with our competence we need to work with the younger and not those with chronic sufferings as schizophrenia. It is the young patient-groups that we in the psychiatric service are working with today, because I think the older patients with chronic psychiatric diseases should be taken care of by the Home Care Service. 


\section{Medication Practice}

The personnel at the shielded shared house took care of the medication in both communities, but this responsibility was not looked after for those who lived in their own home. That was the Home Care service job. The most educated personnel in the mental health team took care of the treatment only in communication with the psychotic persons, while the lowest educated personnel in the Home Care settings administrated the patients' medicine.

The personnel from the mental health team took care of the communication-therapy, but were not in charge of administrating the medicine. Some of the personnel from the mental health team were teachers so they had no knowledge about medication, and that is a problem. Some of the workers in the Home Care service had only a ten hour medical course. They were afraid of the patients who could be aggressive and denied to take their medicine.

One informant says,

In the shielded shared houses, the personnel were trying to teach the patients to administrate their own medicine by user-participation; the personnel guided the patients while the patients themselves took the medicine and took it from the medicine box and put the pills into the pill-dispenser. If the patients needed a depot-injection they had to go to the doctor's office in the municipality, because this is looked on as the doctor's responsibility.

The patients who lived in their own home got all their medicine from the Home Care service there, both pills and depot-injections. The age of these patients varied from 50-80 years of age.

The user participation was taken care of in the Shielding-flat also in medication; the personal guided the patients while the patients themselves took the medicine and put it from the medicine glass and put the tablets into a dose-box. If the patients needed a depot-injection, they had to go to the doctor's office in the municipality, because this was seen upon as a doctor's responsibility. The patients who lived in their own flat got all their medicine from the Home Care settings; both tablets and depot-injections in their own home. The age of these patients varied from 50-80 years of age.

\section{Different Communication Skills}

The personnel in the mental health team in both municipalities had education within communication, mental health, psychiatric treatment, and cognitive therapy, and they were also educated in giving therapy to patients who were addicted to alcohol and drugs. Those who worked in the Home Care service did not have any further education within the psychiatric field, but the leaders pointed out that because of these differences they saw that there was a need of educating the personnel in psychiatric nursing, but also because the personnel were not satisfied with one hour of coaching a month from the mental health field personnel. It was in the daily settings in the patients' home they really needed to be good in communicating, especially when the patients were aggressive and did not want to take their medicine.

\section{Observation of Patients}

During this study, it occurred that the patients were observed very little. The patients were observed in their home, in the psychiatric activity centre and in the shielded shared houses. The patients, who came to the office at the District Mental Health Service to have their therapy session, were seen sometimes only once a week for one hour or less. And the ones who were at the doctor's office to get their depot-injection were observed there for a few minutes. Because the education of the personnel in the Home Care service varies from one year of health educations, to a bachelor's degrees and to no education at all, the possibility to make good 
observations will vary too, especially when the personnel gets scared and leaves the patients after just a few minutes.

\section{The Home Visitors' Role}

The roles of the home visitor differed, but there were no special differences between how the organization of the visitors' role was pointed out in these two municipalities. If the patient was aggressive they went two and two to visit them both in the shielded shared house and in the patient's own home, but there were no cooperation between the Home Care service personnel and the District Mental Health Service personnel. There was a variation in how this was taken care of. In the patients home the most usual was to visit the patient alone. To visit patients in their own home, the visitor needs to show respect, and as a health worker they need to have education and experiences in how to take care of patients who suffer from psychosis.

\section{Caring in Practice}

Caring in practice home and shielded shared house flat was to let the patients be in focus, to let them participate in decisions that regarded themselves. The practice was to let the user decide when they needed to care for themselves (take a bath), their home (washing, vacuuming) and to do grocery shopping to make themselves breakfast, dinner, etcetera. The District Mental Health Service personnel usually went to cafés and did other daily activities together with the patients. When visiting official offices and going to the sheltered workshops, the District Mental Health Service personnel usually went together with the patients. The Home Care service staff helped the patients care for themselves, and they administrated medication.

\section{Discussion}

The challenge for the health workers in this study is to observe the side effects of the medicine and adverse reactions, and also to be aware of complications, and our findings show that the personnel with education within the psychiatric field should be the ones administrating the medicine, and observing to see if there are any effects, side-effects, and/or adverse reactions. An alternative would be to hire psychiatric health workers in the Home Care service. The patients' body and soul is separated in the way the organization of the care is planned for. The Norwegian researcher Tønnessen's (2011) doctoral study called "The Challenge to Provide Sound and Diligent Care". A qualitative study of nurses' decisions about prioritization and patients' experiences of the home nursing service" shows that the Home Care Service has a lower standard according to the political specification sheets. There is no coherence between the task they have and the recourses they are given. She interviewed 17 nurses and 9 patients in the Home Care service in Norway. The amount of time and recourses were not the best according to the giving of nursing; this was pointed out both by nurses and patients. Caring for the patients psycho-social needs were particularly lacking, and can be compared to what we found in the Home Care service. The service practice and the medication practice in our study was depending on the nurses in the Home Care service, and can be compared to Besenius et al.'s (2010) who points out that the relationship between the nurse and the patients needs to be good and reliable in order to reach the aim of a therapeutic intervention. Muir-Cochrane (1998) also focuses on the nurse's ability to communicate with the patients while visiting him at his home, and the time for observing the patient. "Caring in practice" as the Norwegian professor in nursing Martinsen (1989) puts it, depends on the nurse's ability to care for others, and is linked to the patient's need of caring. Caring should not be separated into body and mind; one should care for the entire patient. Because of the medication practice and the observation of patients in our study, we are 
worried. Birkenæs et al.'s (2006) study on risk factors for patients with mental health illness, show that cardiovascular risk factors is higher for patients with severe mental disorders compared to the general population. To reduce side effects as over-weight, it is important that health workers can inform the patients about actual side effect and nutrition plans. Johannessen et al. (2011), points out that there are problems concerning who is responsible for the nutrition of the psychiatric patients. In our study, the mental health workers was occupied with communication-treatment with the patients, but had lack of information and knowledge about psychopharmaca and neuroleptica. Conflicts arise when the health workers should give medications to the patients, because the patients did not always accept or remember to take the medicine. According to Cradock-O Leary et al. (2002), service users over 50 years old with bipolar disorders received less general medical care than people with other mental disorders.

The role of the mental health workers is changing because of more focus on empowerment and the patients need for autonomy (Opptrappingsplanen for Psykisk helse, 2003) (Psykisk helsearbeid for voksne i kommunene, 2006)(Pasient-og brukerrettighetsloven, 1999). Even though the users' participation is in focus, there are patients that cannot take care of themselves and are in need of caring. The role of the health workers is important for the well-being and the quality of their health. Some of the mentally ill patients can also be coached in how to know their own body and mind and can take care of themselves. This focus on coaching or preseptorship in nursing is shown in an article by Sæterstrand and Møllersen (2010). Their study shows that the patients were in need of expert advises given from nurses, and they needed to have their different questions about their health and illnesses answered - and these questions can only be answered by professionals who knows what they are talking about, not answered by teachers or social workers.

What occurs to us in this study is that the health worker who visits the patients in their home needs more knowledge about mental illnesses, the psychofarmaca and neuroleptica given, and its side effects, and they also need knowledge about how to communicate with a psychiatric patient.

The selection of informants in our study is small, consisting of only eight persons, but the findings can still provide a picture of a professional role and the responsibility the care giving person has when taking care of patients with mental illnesses who live in their homes and are rarely visited, and thereby also, rarely observed properly.

\section{Conclusion}

The organization of the medication responsibility needs to be focused more on because of the need of good observation of both the effects and side effects on the patients. The practice of administrating medicine in these two municipalities, and in this research, is not the practice in all municipalities.

The meaning of a greater cooperation between psychiatric health service and the home care service when it comes to medication administration occurred in this study, but also at the same time, it occurred that this cooperation was not always good enough.

The study can contribute to a change of attitude within the health personnel when it comes to medication administration. It can contribute to give guidelines for how the psychiatric health service can involve itself in the home care service. Such guidelines will in the next round have an importance for the quality of the care for the individual patient. But there is a need for more research on medicine administration, and a study of the health personnel's descriptions of their experiences of the cooperation will contribute to cast a light on the research field. 


\section{References}

Besenius, C., Clark-Carter, D., \& Nolan, P. (2010). Health professionals' attitudes to depot injection antipsychotic medication: A systematic review. Journal of Psychiatric and Mental Health Nursing, 17(5), 452-462.

Birkenaes, A. B., Søgaard, A. J., Engh, J. A., Jonsdottir, H., Ringen, P. A., Vaskinn, A., ...Andreassen, O. A. (2006). Socio-demographic characteristics and cardiovascular risk factors in patients with severe mental disorders compared with the general population. J. Clin Psychiatry, 67(3), 425-433.

Cocoman, A., \& Murray, J. (2008). Intramuscular injections: A review of best practice for mental health nurses. Journal of Psychiatric \& Mental Health Nursing, 15(5), 424-434.

Cradock O-Leary, J., Young, A. S., Yano, E. M. et al. (2002). Use of general medical services by VA patients with psychiatric disorders. Psychiatric Service, 53, 874-878.

Gray, R., Smedley, N., \& Thomas, B. (1997). The administration of PRN medication by mental health nurses. Journal of Psychiatric and Mental Health Nursing, 4(1), 55-56.

Johannessen, B., Skagestad, I., \& Bergkaasa, A. M. (2011). Food as medicine in psychiatric care: Which profession should be responsible for imparting knowledge and use of omega-3 fatty acids in psychiatry. Complement Ther Clin Pract., 17(2), 107-112.

Krueger, R. A. (1994). Focus groups: A practical guide for applied research. London: Sage Publications.

Kvale, S. (1997). Interview: En introduktion til det kvalitative forskningsinterview. København: Hans Reitzels Forlag.

Martinsen, K. (1989). Omsorg, sykepleie og medisin. Oslo: Tano

Menza, M., Vreeland, B., Minsky, S., et al. (2004). Managing atypical antipsychotic-associated weight gain: 12 month data on a multimodal weight control program. Journal of Clinical Psychiatry, 65, 471-477.

Muir-Cochrane, E. C. (1998). The role of the community mental health nurse in the administration of depot neuroleptic medication: 'not just the needle nurse! International Journal of Nursing Practice,4(4),254-260.

Veileder for Psykisk helsearbeid for voksne i kommunene. (2006). Oslo: Sosial-og helsedirektoratet.

Lov om pasient og brukerrettigheter. (1999). Oslo: Sosial og helsedepartementet.

Opptrappingsplanen for psykisk helse. (1999-2006). Oslo: Sosial-og helsedirektoratet.

Sæterstrand, T., \& Møllersen, A. (2010). Sykepleiernes erfaringer med brukerveiledning i psykiatrisk dagsenter. Vård $i$ Norden, $30(1), 19-23$.

Phillips, L., \& McCann, E. (2007). The subjective experiences of people who regularly receive depot neuroleptic medication in the community. J. Psychiatr.Ment.Health Nur, 14(6), 578-586.

Poole, I., \& Grimes, P. (1998). Depot injections at home or clinic? Letting clients choose. Community Nurse, 4(1), 15-16.

Tønnessen, S. (2011). The challenge to provide sound and diligent care: A qualitative study of nurses' decisions about prioritization and patients' experiences of the home nursing service. Oslo: University in Oslo.

Rock, D. (2000). Does drawing up technique influence patients'perception of pain at the injection site? The Australian and New Zealand Journal of Mental Health Nursing, 9(3), 147-151.

Wynaden, D. et al. (2006). Best practice guidelines for the administration of intramuscular injections in the mental health setting Int. J. Ment. Health Nurs, 15(3),195-200. 